\title{
On the Connection between the 2008-2009 Activation of the Koryakskii Volcano and Deep Magmatic Processes
}

\author{
V. O. Mikhailov ${ }^{a, b}$ *, M. S. Volkova ${ }^{a}$, E. P. Timoshkina ${ }^{a}$, N. M. Shapiro ${ }^{a, c}$, and V. B. Smirnov ${ }^{a, b}$ \\ ${ }^{a}$ Schmidt Institute of Physics of the Earth, Russian Academy of Sciences, Moscow, 123242 Russia \\ ${ }^{b}$ Faculty of Physics, Moscow State University, Moscow, 119991 Russia \\ ${ }^{c}$ Institut des Sciences de la Terre, Université Grenoble Alpes, CNRS (UMR5275), Grenoble, 38400 France \\ *e-mail:mikh@ifz.ru
}

Received March 15, 2021; revised March 22, 2021; accepted March 22, 2021

\begin{abstract}
The last activation of the Koryakskii volcano in 2008-2009 was accompanied by intense fumarolic and seismic activity. Volcanic activity peaked in March-April 2009 when ash plume rose to a height of $5.5 \mathrm{~km}$ and extended laterally over more than $600 \mathrm{~km}$. To understand the dynamics of the volcanic processes and to forecast the further course of the events, it is relevant to establish whether the eruption was associated with a rise of magma to beneath the volcanic edifice or caused by fracturing of the volcano's basement and penetration of groundwater into a high temperature zone. Based on the analysis of the images from the Japanese satellite ALOS-1 using satellite radar interferometry methods, the slope displacements of the Koryakskii volcano during its last activation have been estimated for the first time. The displacements reach $25 \mathrm{~cm}$ and cannot be explained by the formation of a layer of volcanic ash deposits or by the slope processes. The most likely cause of the displacements should be recognized to be the intrusion of magmatic material into the volcano edifice with the formation of a fracture with its lower edge at a depth of $0.5 \mathrm{~km}$ above sea level, with a size of 1.0 and $2.4 \mathrm{~km}$ along the strike and dip, respectively, and with a dip angle from $45^{\circ}$ to $60^{\circ}$. Therefore, the processes taking place beneath the volcano can be threatening to the nearby localities and infrastructure and require continuous monitoring.
\end{abstract}

Keywords: Koryakskii volcano, 2008-2009 eruption, SAR interferometry, slope displacements, dike intrusion

DOI: $10.1134 / \mathrm{S} 1069351321060045$

\section{INTRODUCTION}

The Koryakskii stratovolcano is located in the southern part of the Kamchatka Peninsula. It is the largest volcano in the Avachinskii-Koryakskii group of volcanoes (AKGV) located in the immediate vicinity of Petropavlovsk-Kamchatskii, the largest city of the peninsula. Studying the volcanic and seismic processes taking place in the AKGV region, the periods and causes of their activation, and eruption forecasting are critically important for people living in this most densely populated part of the peninsula.

According to (Ivanov, 2010), Koryakskii volcano reactivated at least 15 times since the 19th century. Three activations (in 1926, 1956-1957, and 20082009) were most powerful and were accompanied by the expulsion of huge volumes of steam and gases with an admixture of ash. The last eruptions began in November 2008; however, high seismic activity with maximum energy class $K \max =8$ has been recorded in the region of the volcano since March 2008 and continued in 2009. Such a substantial number of seismic events have been observed for the first time since
November, 1992 when the Kamchatka Branch of the United Geophysical Survey of the Russian Academy of Sciences (KB UGS RAS) began detailed observations at AKGV. Fumaroles were located on the western slope close to the volcano's summit along a fissure that emerged during the 1956-1957 eruptions. Volcanic activity peaked in March-April 2009. A visible plume rose to a height of up to $5.5 \mathrm{~km}$ and extended laterally over $600 \mathrm{~km}$ (Girina et al., 2010).

Some authors attribute the activation of the Koryakskii volcano to the processes in the magma chamber. For example, Ivanov (2010) relates the eruption to a gaseous one with ash emission rather than to phreatic. He concluded that this eruption is associated with magma rise and intrusion to a depth of $10-14 \mathrm{~km}$ into the submeridional fissure which flanks the volcano in the north. The analysis of the KB UGS RAS catalogs for the period from January 2000 to February 2013 which contain more than 3000 earthquakes occurred in the AKVG edifices and basement has shown that the 2008-2009 activation of the Koryakskii volcano was caused by the injection of magma from the magma sources of Avacha and Koryakskii 
volcanoes (Kiryukhin et al., 2017). The authors of the cited work believe that the pre-eruption period began with the saturation of the crustal magma chamber with its top at a depth of $3 \mathrm{~km}$ below sea level (bsl). The subsequent magma injection into a $7.5 \times 2.5 \mathrm{~km}$ submeridional zone in the depth interval from 2 to $5 \mathrm{~km}$ bsl in the northern sector of the Koryakskii volcano coincided with the period of most intense summit steamgas eruption (February 2009 to March 2010). Magma injection was accompanied by the intrusion of the inclined dikes with dip angles from $34^{\circ}$ to $87^{\circ}$. Modeling of magma injection was carried out in (Kiryukhin et al., 2017) for a $2 \times 2 \mathrm{~km}^{2}$ fissure with a dip angle $60^{\circ}$ and a depth $4 \mathrm{~km}$ bsl.

The tomographic models of the AKVG region based on the KB UGS RAN catalogs for the period from January 1, 2009 to December 31, 2018 (2019) and ambient seismic noise tomography (Koulakov et al., 2014) show the presence of a low-velocity zone at a depth of $\sim 7 \mathrm{~km}$ beneath the Koryakskii volcano. This zone can be associated with a permanent magma source which was the origin of the rise of magma.

The analysis of thermal structure of the gas-andash explosive plumes carried out in (Gordeev and Droznin, 2010) estimates the total mass of water vapor over the eruption period (100 days) at $3 \times 10^{5} \mathrm{t}$ and the total thermal energy of the eruption at $10^{9} \mathrm{MJ}$. It is logical to associate the source of such an amount of heat with the intrusion of magma. This energy can be obtained, e.g., under the crystallization of magma with a volume of $10^{6} \mathrm{~m}^{3}$ (Gordeev and Droznin, 2010).

At the same time, based on the results of grain size analysis, chemical, and mineralogical analyses of ashes emitted by the 2008-2009 eruption, Anikin et al. (2011) and Maksimov et al. (2011) concluded that the 2008-2009 activation was not directly related to the motions of magma in the volcanic chamber but was caused by fracturing of the heated rocks of the volcano basement and groundwater intrusion into the hot zone. A similar conclusion is present in (Girina et al., 2010). The causes of intense seismicity in a wide depth range are not discussed in these works.

Thus, the questions of what was a cause of activation of the volcano and is there an evidence of magma rise to beneath the volcanic edifice are highly relevant. Solving these questions is important not only for understanding the dynamics of the volcanic processes but also for forecasting the further developments of the events and their threat to the population, infrastructure, and aviation.

Using SAR interferometry data, we determined for the first time the displacements of the slopes of the Koryakskii volcano during the period of 2008-2009 and thus contributed to the solution of the above questions. In this paper, we present the estimation results on the displacements of the volcano surface based on the analysis of images from the Japanese satellite ALOS-1 and the interpretation of the displacement field within the model of dike formation under the surface of the volcano. The Conclusions section discusses the probable causes of volcano activation.

\section{SURFACE DISPLACEMENTS OF THE KORYAKSKII VOLCANO ESTIMATED BY SAR INTERFEROMETRY}

The method for estimating ground displacements from satellite measurements by synthetic aperture radars (SAR interferometry) is following. The radar transmits a signal in a certain wavelength range and detects the reflected signal. A radar image is a matrix of complex numbers containing the amplitude and phase of the reflected signal. If there are two images from close points, then, knowing the height of the satellite above the ellipsoid (HAE), the distance (baseline) between the imaging points, and the angle of incidence of the radar beam, one can determine the height of an element of the Earth's surface above the ellipsoid, i.e., the digital elevation model (DEM). The phase of the radar signal reflected from a given element on the Earth surface during a repeated survey changes because of the change in the spatial position of the radar and probable spatial displacements of the reflecting element with time, therefore the signal from two different survey points comes with a different phase. The pixel image in terms of phase differences is a differential interferogram. Using the previously derived DEM, one can estimate the displacement of the reflecting element since the time of the previous survey (e.g., (Dmitriev et al., 2012; Mikhailov et al., 2013)).

Satellite images are taken in different frequency bands. In the complex topographic conditions of the Kamchatka region, the most suitable images for interferometric processing are obtained in the $C$-band (wavelength $\lambda=5.6 \mathrm{~cm}$ ) and, especially, $L$-band $(\lambda=$ $23.6 \mathrm{~cm}$ ) because at higher $\lambda$, radiation has better penetrability and, thus, the quality of the processing results is less impaired by the time decorrelation from atmospheric noise, snow cover, and vegetation.

For the activation period of the Koryakskii volcano, we found seven ALOS-1 satellite images in the database of the Japan Aerospace Exploration Agency (JAXA). One image was rejected because of a long baseline and low coherence. The images map the ground surface as of June 21, 2006; August 16, 2007; May 18, 2008; October 6, 2009; May24, 2010; August 24, 2010, and October 9, 2010.

For the selected AKVG region, we calculated interferograms for different image pairs. The best results were from the image pair August 16, 2007 and October 6, 2009 the interval between which covers the entire eruption period. An important fact is that on the days of the survey, substantial territory of the slopes was free of snow cover. 
The interferograms were calculated using the SARscape software with pixel averaging perpendicular to the orbit so that the resolution cell was as large as $14.98 \times 12.29 \mathrm{~m}$. Phase filtering was carried out by the Goldstein method. The interferometric coherence of the image pair is high for natural terrains $(>0.6)$. As the displacements are determined from the phase shift of the signals reflected from the same scatterer during the repeated imaging, the displacements on the interferogram are expressed in radians and wrapped modulo $2 \pi$. The absolute phase is determined by unwrapping, i.e., adding the number of full periods ( $2 \pi$ multiples) corresponding to the path-length difference. To unwrap phase, we used minimum cost flow algorithm. After passing from radar coordinates to geographic coordinates, we constructed a map of displacements in $\mathrm{m}$ (Fig. 1).

The displacements are determined in the line-ofsight (LOS) direction. Their values on a selected area range from -33 (from the satellite) to $22 \mathrm{~cm}$ (towards the satellite). Assuming that displacements mainly occur in the vertical direction, then, with an average incidence angle of the satellite beam of $38.69^{\circ}$, the displacements in the directions towards the satellite should be multiplied by 1.28 .

Areas of negative displacements are spotted on the slopes of all volcanoes on the image and can be primarily associated with erosion. Within the image there is only one area of the uplifts on the northwestern slope of the Koryakskii volcano around the 20082009 eruption zone. The displacements increase from $9-15 \mathrm{~cm}$ at the foot to $20-22 \mathrm{~cm}$ towards to summit. Assuming that the displacements are purely vertical, we obtain that the displacements at the summit are above $28 \mathrm{~cm}$.

We stress that the positive displacements on the northwestern slope of the Koryakskii volcano can barely be associated with the increase in the thickness of snow cover and glaciers in the vicinity of the summit or with the formation of a layer of ash deposits. According to (Maksimov et al., 2011), the ashes, as a rule, had insignificant thickness and occurred as separate patches on the snow even at a small distance from the eruptive center. The cited work reports ash deposits with a thickness of a few $\mathrm{cm}$. This is also clearly visible in many photo images presented on the Internet and in the articles (e.g., (Girina et al., 2010; Ivanov et al., 2010; Maksimov et al., 2011)). Moreover, it reported on melting of glaciers and on the formation of deep troughs in them due to the reduction of reflectivity of ice. These processes should have caused a surface to subside. Therefore, volcano surface uplifts with the amplitude up to $25 \mathrm{~cm}$ cannot be attributed to the formation of the ash layer.

The persistent ash emissions throughout the 20082009 eruption and the analysis of seismicity (Kiryukhin et al., 2017) indicate that magma could approach close to the volcano's surface. The total vol- ume of the uplifts on the northwestern slope of the volcano (Fig. 1) is $1.3 \times 10^{6} \mathrm{~m}^{3}$. In the model of an dilating fault (Okada, 1985), this value is approximately equal to the volume of the opened space. This is very close to the estimate obtained by Gordeev and Droznin (2010) for the volume of magma $\left(10^{6} \mathrm{~m}^{3}\right)$ required whose cooling can provide the observed steam emission and to the value of opening of a fissure with a volume of $1.2 \times 10^{6} \mathrm{~m}^{3}$ in the model (Kiryukhin et al., 2017). This indicates that the uplifts of the volcano slope just as the other observed processes are most likely to be associated with the intrusion of magma material. This hypothesis in considered below.

\section{NUMERICAL INTERPRETATION OF THE DISPLACEMENT FIELD}

To interpret the displacement field we used the solution (Okada, 1985) about surface deformation of an elastic half-space due to the displacement along a rectangular fault located in it. In the general case, the displacement vector includes three components: tensile (TS) reflecting extension, dip-slip (DS) component describing the up-dip or down-dip displacement along the fault plane, and a strike-slip (SS) component corresponding to the displacement along the strike. Application of this solution in our case is challenging because the solution is obtained for the displacements along a crack located in an elastic halfspace with a horizontal free surface. Within the displacement region shown in Fig. 1, the terrain elevations vary from 1300 to $3450 \mathrm{~m}$ (Fig. 2a); therefore, the neglect of the real topography can lead to errors. To mitigate the terrain effect, we converted the displacement map into the local Cartesian coordinates and approximated the relief in the region with LOS displacements above $10 \mathrm{~cm}$ by a plane. Then, the coordinate system was rotated around the $O z$ axis by an angle of $43.03^{\circ}$ (the rotation direction is shown by red arrow in Fig. 2a) so that to make the $O x$ axis parallel to the projection of the approximating plane gradient vector onto the $x O y$ plane (Fig. 2b). Within the displacement map, the heights of the approximating plane vary within $2.15 \mathrm{~km}$ and terrain elevations relative to this plane (Fig. 2b) range from -220 to $220 \mathrm{~m}$.

Next, the coordinate system was rotated by an angle of $27.3^{\circ}$ around the $O y$-axis so that the $O z$-axis was perpendicular to the approximating plane. In the new coordinates, the plane approximating the relief coincides with the free surface of the elastic half-space and the deviations of the residual relief (Fig. 2b) prove to be small compared to a fracture depth. Now, as a distance from the fracture to the ground surface, in formulas of (Okada, 1985) we can either use the very distance to the approximating plane or to add to this distance the height of the local topography above this plane. Calculations have shown that with the heights of the local relief in the study region, this does not cause a significant change in the solution. After solv- 


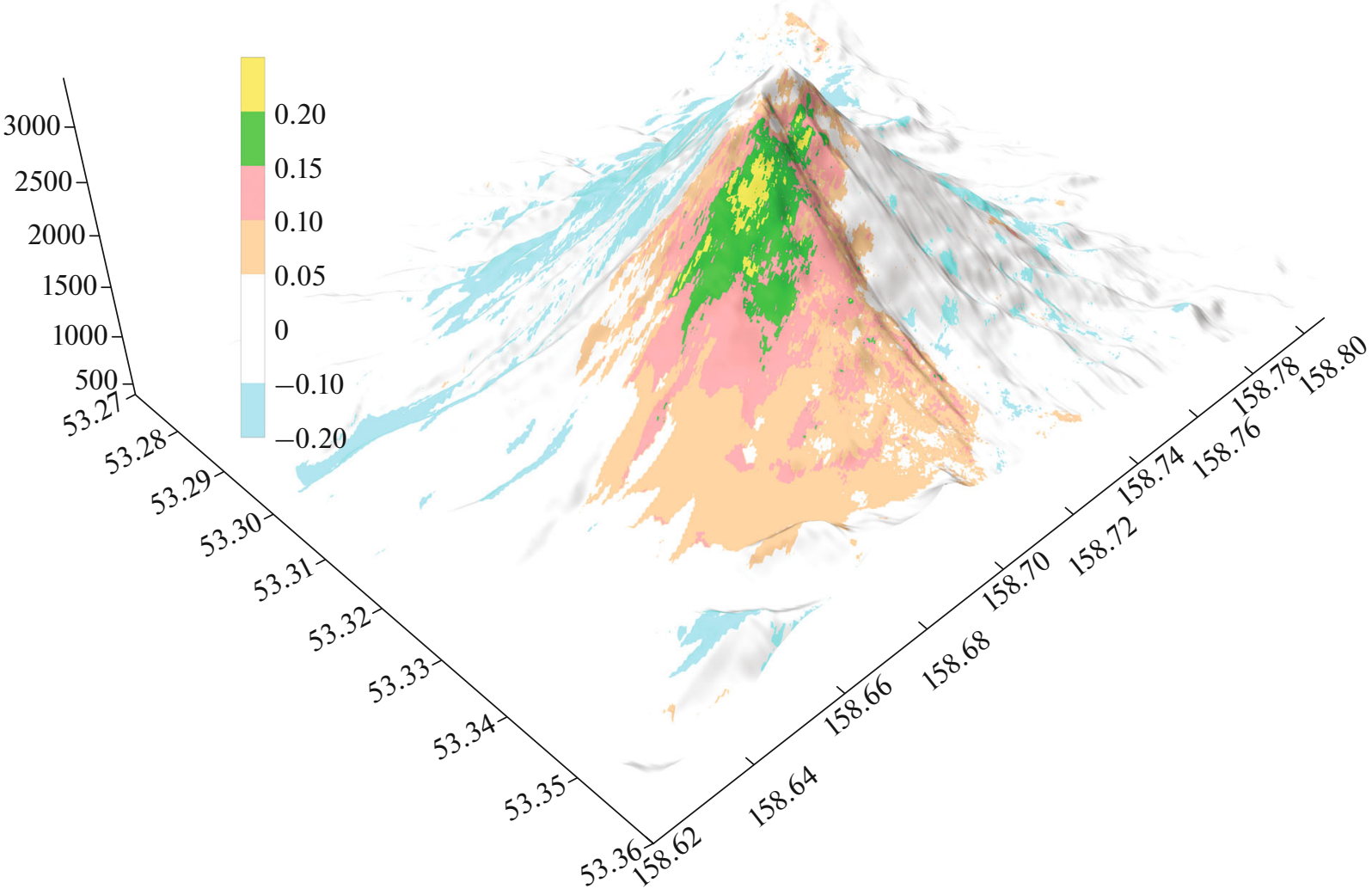

Fig. 1. Displacements (color scale in $\mathrm{m}$ ) obtained from paired interferogram based on images of August 16, 2007 and October 6, 2009. Negative and positive values are displacements in the direction away from and towards the satellite. Shadow relief is based on SRTM DEM. Vertical scale is terrain elevations in $\mathrm{m}$, horizontal scale is coordinates in degrees.

ing the inverse problem, the displacement field on the surface of the model is rotated back to the local coordinate system (Fig. 2b), and LOS displacement is calculated using the flight path azimuth and the incidence angle of radar beam (for ALOS-1 ascending track, $-8.16^{\circ}$ and $38.69^{\circ}$, respectively).

The solution from (Okada, 1985) is widely used in modeling seismic and volcanic processes and, therefore, the effects of terrain topography and structural heterogeneity of the medium have been discussed on many occasions in the literature (e.g., (Armigliato and Tinti, 2003) and references therein). Terrain effect is determined by the ratio of topographic height difference to the depth of the deformation source. In our case, terrain fluctuations relative to the approximating plane are $0.2 \mathrm{~km}$, when to the of the dike is $\sim 1.5-2 \mathrm{~km}$ depending on the assumed dip angle.

In the solution (Okada, 1985), a fracture is approximated by a rectangular element or a set of elements. We only considered a single rectangular element which ensures numerical stability of the inverse problem. A rectangular element is characterized by ten parameters. These are the three coordinates of the center of the lower edge of the rectangle; its dip and strike dimensions; the dip and strike angles; and the three components of the displacement vector $(T S, D S$, and $S S$ ). The displacement field on the surface is a linear function of the three components of the displacement vector; the dependence on the other parameters is nonlinear.

The size of the displacement region and the characteristic distance from the maximum to the halfmaximum of the displacement field on the ground depend on the fracture depth and size. We selected the parameters of the rectangle based on the analysis results of seismic event distribution, in particular in Fig. 4 of (Kiryukhin et al., 2017) where the upper cluster of earthquakes is located below the Koryakskii volcano at a depth level of $0.5 \mathrm{~km}$ above sea level and shallower. The modeling in this work was conducted for a fissure with a size of $2 \times 2 \mathrm{~km}^{2}$ and a dip angle $60^{\circ}$. The lower edge of the rectangular element was located at a depth of $0.5 \mathrm{~km}$ above sea level as suggested by the dimensions of the displacement region. The dip and strike dimensions were assumed to be 2.4 and $1.0 \mathrm{~km}$, respectively. The dip angle was varied within $45^{\circ}-80^{\circ}$. The coordinates of the lower edge and the strike of the rectangle can be easily selected by shifting the maps of 
(a)

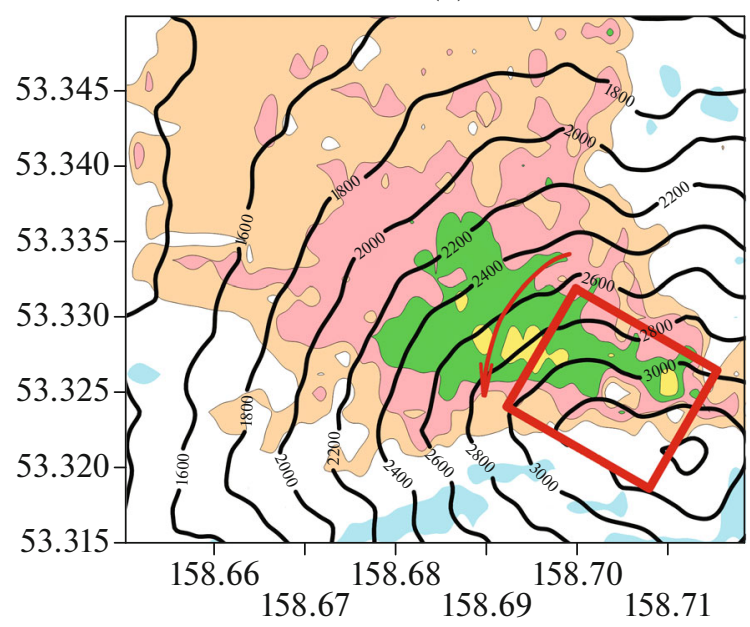

(b)

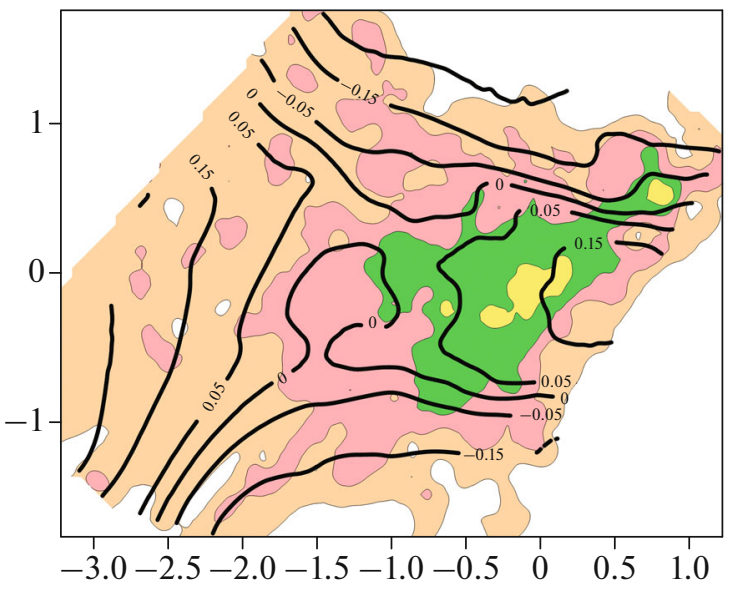

0.20

0.15

0.10

0.05

0

$-0.10$

$-0.20$

Fig. 2. Displacements in the direction towards satellite (color scale, $\mathrm{m}$ ) on western and northwestern slope of Koryakskii volcano: (a) map in geographic coordinates, isolines show height above sea level in m. Red arrow is direction of rotation around $O z$ axis; (b) map in local Cartesian coordinates after subtraction of plane approximating local relief and rotation around the $O z$ axis. Isolines show height above approximating plane in $\mathrm{m}$.

(a)

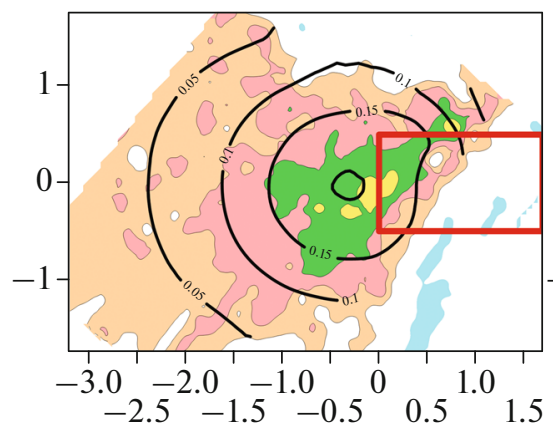

(b)

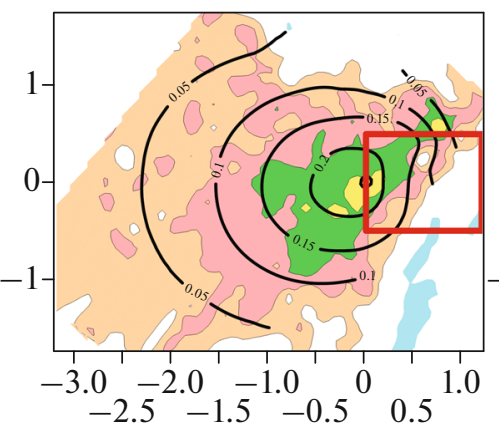

(c)

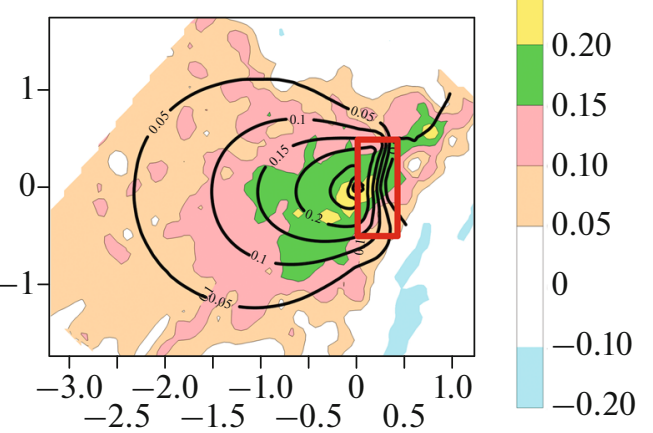

Fig. 3. Model of fissure in volcanic structure of Koryakskii volcano. Displacements in direction towards satellite are shown by color (meters), isolines are the calculated LOS displacements in m: (a), (b), (c) models with dip angle $45^{\circ}, 60^{\circ}$, and $80^{\circ}$. Red rectangle is projection of fissure on horizontal plane.

the calculated and measured displacement field relative to each other. Following (Kiryukhin et al., 2017), we set the displacements along the fissure strike to be zero $(S S=0)$ and determined two componentsextension $(T S)$ and dip-slip displacement $(D S)$-by solving a system of linear equations.

The best fit of the LOS displacement field is achieved with the fissure dip angles in the interval from $45^{\circ}$ and $60^{\circ}$ (Fig. 3). In all models, the normal dip-slip displacement component is a few $\mathrm{cm}$, i.e., zero within the accuracy. The extension at the dip angles $45^{\circ}, 60^{\circ}$ and $80^{\circ}$ is 82,71 , and $64 \mathrm{~cm}$, respectively. Thus, the volume of the injected material is $2.0 \times 10^{6}, 1.7 \times 10^{6}$, and $1.5 \times 10^{6} \mathrm{~m}^{3}$, respectively, which is consistent with the above data of other authors. The model with one rectangular fracture fairly well approximates the real displacement field; therefore, in our opinion, it was unreasonable to complicate the model.

\section{CONCLUSIONS}

1. The surface displacements of the Koryakskii volcano estimated by SAR interferometry are larger than $25 \mathrm{~cm}$ and cannot be explained by the ash layer formed during the eruption of 2008-2009. Slope processes and glacier melting should have produce displacements of the opposite sign. Therefore, as the most likely cause of the observed displacements, we should recognize the injection of magmatic material into the volcano structure. This is also suggested by the analysis of seismic catalogs and the results of thermal imaging studies.

2. A fissure model with a lower edge at a depth of $0.5 \mathrm{~km}$ above sea level, a width of $1.0 \mathrm{~km}$ along the 
strike and $2.4 \mathrm{~km}$ along the dip, and a dip angle from $45^{\circ}$ to $60^{\circ}$ fairly well fits the displacements identified by SAR interferometry. Fissure volume is consistent with the estimates of other authors (Gordeev and Droznin, 2010; Kiryukhin et al., 2017). We note that the depth of the fissure can be increased by $1 \mathrm{~km}$ with the corresponding reduction of its geometrical dimensions.

3. The obtained results support the hypothesis that the activation of the Koryakskii volcano was associated with the ascent of volcanic material and its injection, inter alia, into the volcanic structure of the volcano itself. Therefore, the processes taking place beneath the volcano can be threatening to the nearby localities and infrastructure and require continuous monitoring.

\section{ACKNOWLEDGMENTS}

We are grateful to the Japan Aerospace Exploration Agency (JAXA) for providing ALOS satellite images under the ER2A2N075 project.

\section{FUNDING}

The work was supported by the Ministry of Science and Education of the Russian Federation under project no. 14.W03.31.0033 "Geophysical studies, monitoring, and forecasting the development of catastrophic geodynamical processes in the Far East of the Russian Federation."

\section{OPEN ACCESS}

This article is licensed under a Creative Commons Attribution 4.0 International License, which permits use, sharing, adaptation, distribution and reproduction in any medium or format, as long as you give appropriate credit to the original author(s) and the source, provide a link to the Creative Commons license, and indicate if changes were made. The images or other third party material in this article are included in the article's Creative Commons license, unless indicated otherwise in a credit line to the material. If material is not included in the article's Creative Commons license and your intended use is not permitted by statutory regulation or exceeds the permitted use, you will need to obtain permission directly from the copyright holder. To view a copy of this license, visit http://creativecommons.org/licenses/by/4.0/.

\section{REFERENCES}

Anikin, L.P., Vergasova, L.P., Maksimov, A.P., Ovsyannikov, A.A., and Chubarov, V.M., Ashes from the eruption of the Koryaksky volcano in 2009, Mater. reg. nauchn. konf., posvyashchennoi Dnyu vulkanologa, "Vulkanizm i svyazannye s nim protsessy” (Proc. Reg. Sci. Conf. on Volcanologists Day "Volcanism and Related Processes"), Petropavlovsk-Kamchatskii, 2011, Petropavlovsk-Kamchatskii: IViS DVO RAN, 2011, pp. 10-14.

Armigliato, A. and Tinti, S., Influence of topography on coseismic displacements induced by the Friuli 1976 and the
Irpinia 1980 earthquakes (Italy) analyzed through a two-dimensional hybrid model, J. Geophys. Res., 2003, vol. 108, no. B12, article 2552 .

https://doi.org/10.1029/2002JB002027

Bushenkova, N., Koulakov, I., Senyukov, S., Gordeev, E.I., Huang, H.-H., El Khrepy, S., and Al Arifi, N., Tomographic images of magma chambers beneath the Avacha and Koryaksky volcanoes in Kamchatka, J. Geophys. Res.: Solid Earth, 2019, vol. 124, no. 9, pp. 9694-9713.

Dmitriev, P.N., Golubev, V.I., Isaev, Yu.S., Kiseleva, E.A., Mikhailov, V.O., and Smolyaninova, E.I., On processing and interpretation of the SAR interferometry data in the case of the landslide monitoring, Sovrem. Probl. Distantsionnogo Zondirovaniya Zemli Kosmosa, 2012, vol. 9, no. 2, pp. 130-142.

Girina, O.A., Manevich, A.G., Mel'nikov, D.V., Nuzhdaev, A.A., Ushakov, S.V., and Konovalova, O.A., The activity of Koryaksky volcano from October 2008 til October 2009 (based on KVERT data), Mater. reg. nauchn. konf., posvyashchennoi Dnyu vulkanologa (Proc. Reg. Sci. Conf. on Volcanologists Day), Petropavlovsk-Kamchatskii, 2009, Petropavlovsk-Kamchatskii: IViS DVO RAN， 2010, pp. 15-23.

Gordeev, E.I. and Droznin, V.A., Thermal structure of the gas-and-ash plume during eruption of Koryak volcano, Dokl. Earth Sci., 2010, vol. 430, no. 1, pp. 19-21.

Ivanov, V.V., A new cycle of Koryaksky volcano activity in late 2008 and early 2009: evaluation of heat and fluid discharge, a model of magma ascent and a forcast of the current activity, Mater. reg. nauchn. konf., posvyashchennoi Dnyu vulkanologa (Proc. Reg. Sci. Conf. on Volcanologists Day), Petropavlovsk-Kamchatskii, 2009, PetropavlovskKamchatskii: IViS DVO RAN, 2010, pp. 24-38.

Kiryukhin, A.V., Fedotov, S.A., Kiryukhin, P.A., and Chernykh, E.V., Magmatic plumbing systems of the Koryakskii-Avacha Volcanic Cluster as inferred from observations of local seismicity and from the regime of adjacent thermal springs, J. Volcanol. Seismol., 2017, vol. 11, no. 5, pp. 321-334.

Koulakov, I., Jaxybulatov, K., Shapiro, N.M., Abkadyrov, I., Deev, E., Jakovlev, A., Kuznetsov, P., Gordeev, E., and Chebrov, V., Asymmetric caldera-related structures in the area of the Avacha group of volcanoes in Kamchatka as revealed by ambient noise tomography and deep seismic sounding, J. Volcanol. Geotherm. Res., 2014, vol. 285, pp. 36-46.

Maksimov, A.P., Anikin, L.P., Vergasova, L.P., Ovsyannikov, A.A., and Chubarov, V.M., Ashes from the 2009 eruption of Koryaksky volcano and distinguishing features of their genesis, Vestn. KRAUNTs, Nauki Zemle, 2011, vol. 18 , no. 2, pp. 73-86.

Mikhailov, V.O., Kiseleva, E.A., Smolyaninova, E.I., Dmitriev, P.N., Golubeva, Yu.A., Isaev, Yu.S., Dorokhin, K.A., Timoshkina, E.P., Khairetdinov, S.A., and Golubev, V.I., Monitoring of landslide processes on a section of the North Caucasian railway using satellite radar interferometry in different wavelength ranges and a corner reflector, Geofiz. Issled., 2013,vol. 14, no. 4, pp. 5-22.

Okada, Y., Surface deformation due to shear and tensile faults in a half-space, Bull. Seismol. Soc. Am., 1985, vol. 75, no. 4, pp. $1135-1154$.

Translated by M. Nazarenko 